\title{
Recent Advances in Magnetic Levitation: A Biological Approach from Diagnostics to Tissue Engineering
}

\author{
Esra Turker and Ahu Arslan-Yildiz*0 \\ Department of Bioengineering, Izmir Institute of Technology (IZTECH), 35430 Izmir, Turkey
}

\begin{abstract}
The magnetic levitation technique has been utilized to orientate and manipulate objects both in two dimensions (2D) and three dimensions (3D) to form complex structures by combining various types of materials. Magnetic manipulation holds great promise for several applications such as self-assembly of soft substances and biological building blocks, manipulated tissue engineering, as well as cell or biological molecule sorting for diagnostic purposes. Recent studies are proving the potential of magnetic levitation as an emerging tool in biotechnology. This review outlines the advances of newly developing magnetic levitation technology on biological applications in aqueous environment from the biotechnology perspective.
\end{abstract}

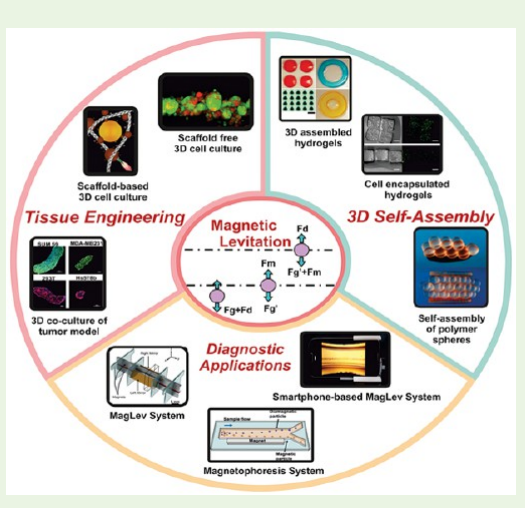

KEYWORDS: magnetic levitation, 3D self-assembly, diagnostics, tissue engineering, 3D cell culture

\section{INTRODUCTION}

As biotechnology advances, innovative tools and instruments are gaining capabilities to overcome obstacles in the biomedical field. Mimicking nature is one of the new trends in biotechnology that has revolutionized current understanding in the fields of tissue engineering, biomedical sensors, and diagnostics. The main challenge associated with mimicking biological systems is the lack of highly sophisticated, controllable tools because current technologies rely on randomized methods that cause problems in functionality and viability. ${ }^{1}$ In this context, the ability to control or intervene in the microenvironment and manipulate biological building blocks such as cells is crucial in both tissue engineering and biomedical fields. ${ }^{2}$ For instance, manipulating biological entities assists in mimicking hierarchical self-assembly of a real tissue that improves the current practice in tissue engineering. In parallel, ${ }^{3}$ controlling the biological microenvironment helps to create an informative platform that gives insight into the complexity of cellular behavior for screening applications. There are several contactless manipulation approaches reported to engineer or control microenvironments while protecting biological delicacy, such as acoustic waves ${ }^{4-9}$ and magnetic levitation. ${ }^{10-13}$

Magnetic levitation is an emerging and powerful tool that offers the ability to control the microenvironment. The method provides antigravity ${ }^{14,15}$ conditions while levitating biological molecules such as bovine carbonic anhydrase (BCA), ${ }^{16,17}$ cells such as Paramecium caudatum, ${ }^{15}$ animal cells, ${ }^{18}$ tissues, ${ }^{19-22}$ and synthetic materials ${ }^{1,23-25}$ incubated in paramagnetic fluid. ${ }^{26,27}$ Magnetic levitation method uses the magnetic force principle, which helps to separate, differentiate, or orientate objects/ biological materials depending on their density differences within a three-dimensional (3D) space. Magnetic levitation has inspired multiple research endeavors to improve method- ologies such as development of a new generation diagnostic tools, ${ }^{28}$ label-free separation of cells and biomolecules, ${ }^{16,17}$ improvement of $3 \mathrm{D}$ cell culture methodologies, ${ }^{29,30}$ and $3 \mathrm{D}$ assembly of micro/nanostructures. ${ }^{1,31}$

Varied components and environmental parameters were used for magnetic levitation; in this review, we mainly focus on the molecular and cellular level biological applications in aqueous environment, especially in the field of diagnostics and tissue engineering. We give an overview of leading studies in the field of magnetic levitation. First, we highlight the current technology, model systems, and working principles. Then, we focus on emerging diagnostic and tissue engineering applications in addition to providing an emphasis on the future perspective and impact.

\section{THEORY}

The magnetic levitation concept was introduced in the 1960s, where a friction-free suspension was enabled for graphite disk under vacuum by utilizing diamagnetic levitation methodology. ${ }^{32}$ Afterward, the magnetic levitation system was developed for density-based mineral ${ }^{33,34}$ and metal separation. ${ }^{35}$ Later, the levitation system was improved for density measurements of solid and organic liquids. ${ }^{36}$ A very well-known example of the magnetic levitation is the levitating frog, where the whole complex organism levitated in the air environment. ${ }^{37-40}$ However, in this review, we mostly focus on biological applications of magnetic levitation concept in aqueous environment, particularly in diagnostic and tissue engineering fields.

The basic principle relies on levitating objects in paramagnetic fluid under a constant magnetic force that positions

Received: September 20, 2017

Accepted: February 6, 2018

Published: February 6, 2018 
(a)

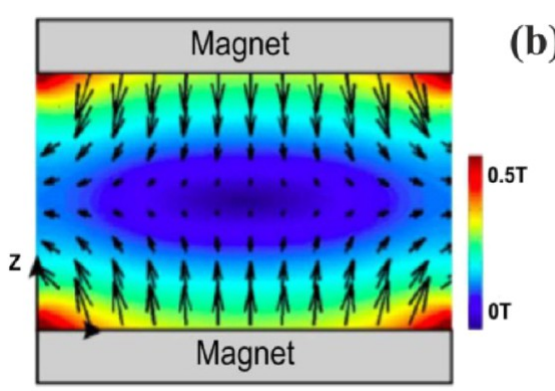

(b)

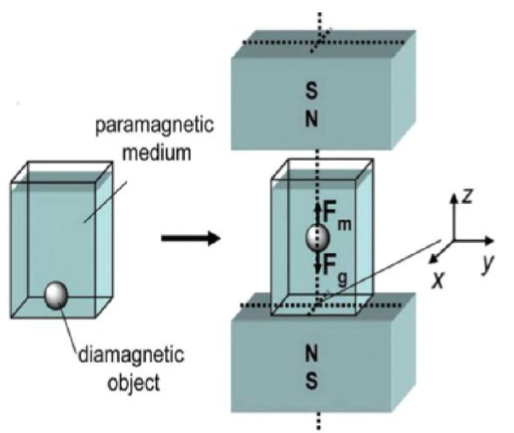

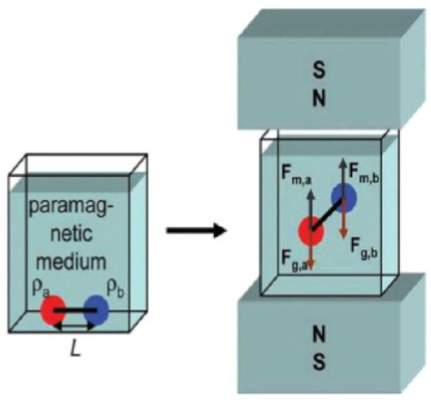

Figure 1. Magnetic levitation theory and technology. (a) 3D magnetic field simulation in the $X-Z$ plane, illustrating flux density (arrows) generated between two NdFeB magnets in anti-Helmholtz configuration. Reproduced with permission from ref 41, Copyright 2016 American Chemical Society. (b) Schematic illustration of basic magnetic levitation setup shows the magnetic $(\vec{F} m)$ and gravitational forces $(\vec{F} g)$ that levitate the object. Basic principle of magnetic levitation; objects levitate to different heights due to density differences. Reproduced with permission from ref 24 , Copyright 2011 John Wiley and Sons.

those objects due to their density differences. Magnetic levitation tools generally consist of two permanent magnets (e.g., neodymium iron boron, $\mathrm{NdFeB}$ ) where the same poles oriented toward each other in an anti-Helmholtz coil configuration to generate a magnetic field and magnetic field gradient (Figure 1a). ${ }^{41}$ High grade (N52) $\mathrm{NdFeB}^{42}$ solid-state magnets generating a magnetic field of $0.4 \mathrm{~T}$ are commonly used for magnetic levitation applications. These magnets introduce strong magnetic forces and ensure a high quality magnetic field for density dependent separation, ${ }^{26,43}$ chemical analysis, $^{26,36,43,44}$ contactless location control, and catching diamagnetic objects in $3 \mathrm{D} .^{43,45-49}$ In a paramagnetic medium (e.g., manganese chloride, $\mathrm{MnCl}_{2}$, aqueous medium), objects are suspended and aligned between two magnets without any external force. ${ }^{23}$ When objects have a different density to the solution, gravitational force, magnetic force, and steric interactions push objects from the center and lead them to either float or sink. Depending on density, a stable levitation height within the paramagnetic fluid arises due to the balance among magnetic and other forces. According to the equation, gravitational $(\vec{F} g)$ and magnetic $(\vec{F} m)$ force balanced while objects levitating. $^{23,26,43}$

$$
\vec{F}_{\mathrm{g}}+\vec{F}_{\mathrm{m}}=\left(\rho_{\mathrm{o}}-\rho_{\mathrm{m}}\right) V \vec{g}+\frac{\left(\chi_{\mathrm{m}}-\chi_{\mathrm{o}}\right)}{\mu_{0}} V(\vec{B} \vec{V}) \vec{B}=0
$$

Here, $\rho_{\mathrm{o}}$ and $\rho_{\mathrm{m}}$ represent density of levitating objects and paramagnetic medium $\left(\mathrm{kg} \mathrm{m}^{-3}\right)$, respectively; magnetic susceptibilities of the object and medium are $\chi_{\mathrm{o}}$ and $\chi_{\mathrm{m}}$, respectively, and magnitude of the magnetic field is $B\left(\mathrm{~A} \mathrm{~m}^{-1}\right)$. Volume sample is $V\left(\mathrm{~m}^{3}\right)$; permeability of free space is $\mu_{0}(1.26 \times$ $\left.10^{-6} \mathrm{~m} \mathrm{~kg} \mathrm{~s}^{-2} \mathrm{~A}^{-2}\right)$, and gravitational constant is $g\left(9.81 \mathrm{~m} \mathrm{~s}^{-2}\right)$.

As illustrated in Figure $1 b,{ }^{24}$ objects with different densities position at the bottom of the container due to the gravitational force. Upon magnetic field exposure, objects begin to levitate based on their density differences.

Magnetic force emerges due to the interaction of two magnets and a paramagnetic medium. ${ }^{25,50}$ There is a gradient in paramagnetic medium depending on the replacement of paramagnetic liquid toward a high magnetic field (Figure 1a). While increasing the volume of the paramagnetic medium where magnetic field potency is high, the potential energy decreases. Therefore, a magnetic levitation system shows replacement of diamagnetic objects in the direction of the center of the container depending on the magnetic force. This replacement takes place in the field where the magnitude is low; if gravitational and magnetic forces become equal, a material levitates constantly in its position. As a result, the levitating object is suspended at a minimum magnetic field strength region based on the magnetic susceptibility difference between levitating objects and paramagnetic media. ${ }^{23,26,43}$

\section{MAGNETIC LEVITATION TECHNOLOGY AND DEVICE FABRICATION}

In recent years, magnetic levitation was developed for separating, $^{28,51}$ classifying, and positioning cells ${ }^{52}$ and other biological substances such as proteins or protein-ligand couples, ${ }^{16,17}$ depending on their physical properties. ${ }^{25}$ It is also employed to guide substances such as hydrogels and elastomers for complex assembly in 3D microenvironment.

One of the earliest magnetic levitation systems, which was developed as a diagnostic tool, was fabricated as a polydimethylsiloxane (PDMS) microfluidic device (Figure 2a). ${ }^{43}$ The microfluidic device was combined with $\mathrm{NdFeB}$ magnets to separate polystyrene particles that differ in density. Diamagnetic polymer particles were suspended in a paramagnetic salt solution, gadolinium chloride $\left(\mathrm{GdCl}_{3}\right)$, and levitated using a magnetic field. Utilized system was able to differentiate and separate particles ranging in diameter from 5 to $5000 \mu \mathrm{m}$, both in static and flow mode. Later, another magnetic levitation system was introduced (Figure $2 \mathrm{~b})^{26}$ which combines a simple cuvette and $\mathrm{NdFeB}$ magnets with the aim of developing a rapid, inexpensive, and direct-forward methodology to quantify the chemical reactions on a solid support. In this system, polystyrene beads were functionalized for chemical reactions and levitated in a paramagnetic solution between two NdFeB magnets. Upon reaction completion, levitation height was changed relying on density of beads (Figure $2 \mathrm{c}$ ). The same system was utilized for a sensitive density-based characterization of both solid materials and liquid droplets. ${ }^{36}$ Densities of diamagnetic solid particles and water-immiscible organic liquids were measured successfully in the range of $1.0-1.7 \mathrm{~g} / \mathrm{cm}^{3}$.

Recently, a new generation magnetic levitation (MagLev) setup has been introduced as "Tilted MagLev" (Figure 2d), which overcomes density-based limitations of previous setups. According to this work, the device was tilted approximately toward the gravitational vector, causing the magnetic force to be decreased. Thus, at ambient conditions, a wide range of density measurements can be made for different materials (Figure $2 \mathrm{~d}$ ), from air bubble $(\rho \approx 0)$ to iridium $\left(\rho \approx 23 \mathrm{~g} / \mathrm{cm}^{3}\right)$. In another study, a high-sensitivity magnetic levitation setup was 
(a)
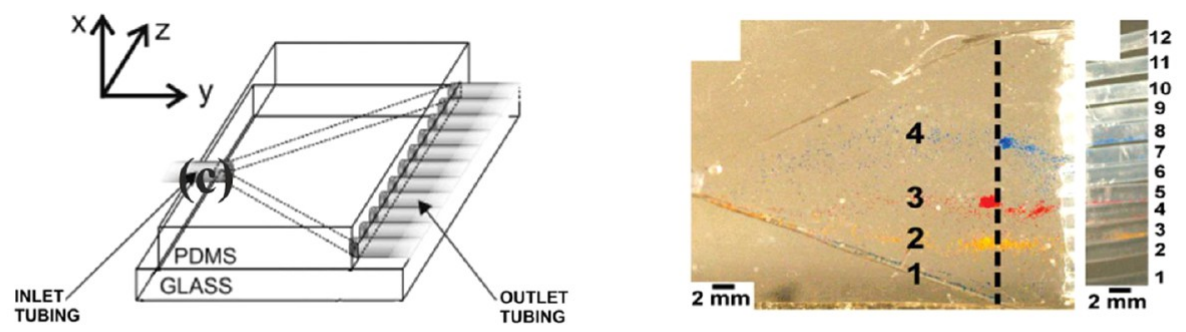

(b)

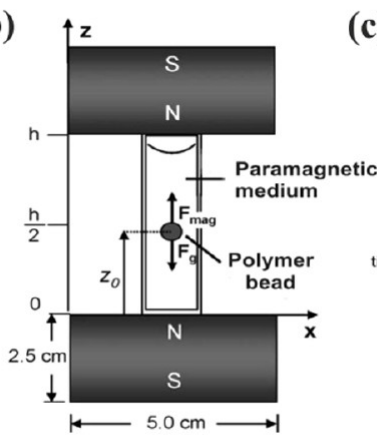

(e)

(f)
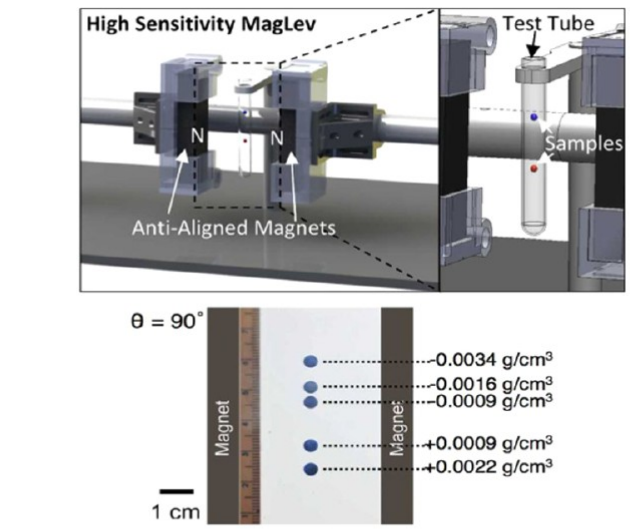

(g) (c)
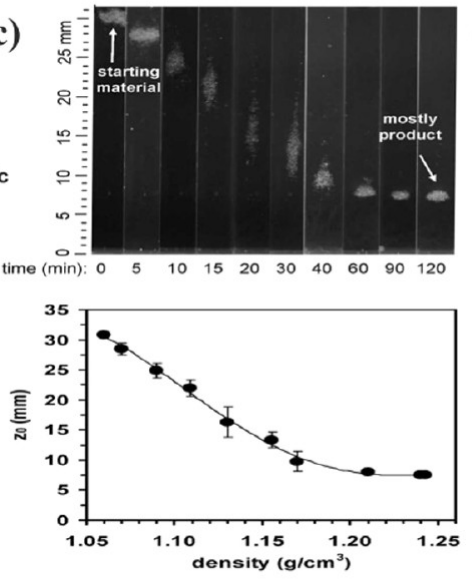

(h)

(d)
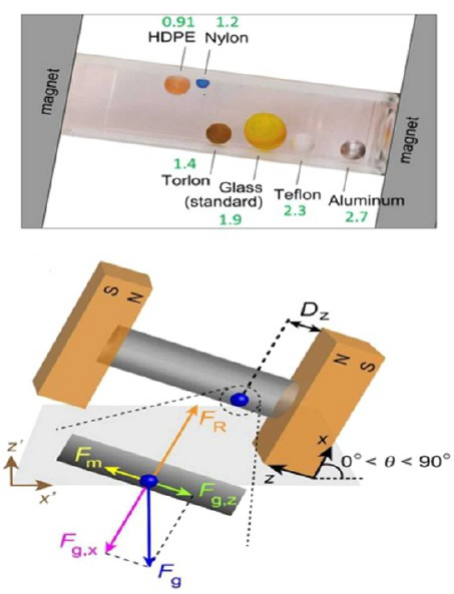
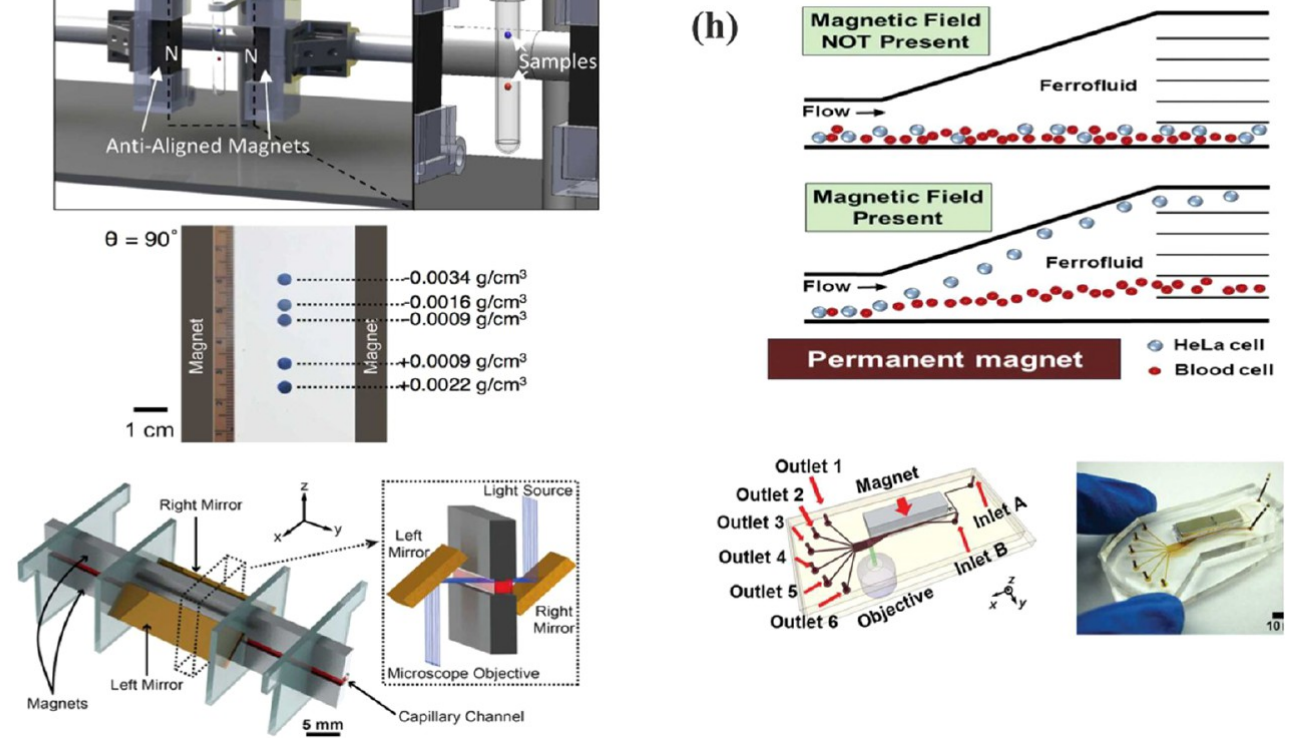

Figure 2. Development of magnetic levitation setups. (a) Schematic illustration of a microfluidic device consisting of separating and collecting channels (left). Magnetic separation of the polymer beads is based on the density differences and collected at the outlet tubing (right). Reproduced with permission from ref 43, Copyright 2007 American Chemical Society. (b) Magnetic levitation setup for monitoring chemical reactions on solid support. Reproduced with permission from ref 26, Copyright 2008 American Chemical Society. (c) Solid-supported chemical reactions are represented, showing levitating clusters of polystyrene beads in different time scales, with each data point on the graph representing the relation between bead density with their levitation height. Reproduced with permission from ref 26, Copyright 2008 American Chemical Society. (d) Basic "tilted MagLev" setup with tilted to the gravitational axis (bottom); top image illustrates spherical objects levitated depending on their varied densities. Reproduced with permission from ref 50, Copyright 2016 American Chemical Society. (e) Schematic representation of the high sensitivity MagLev device which can measure densities of objects in rotating configuration. Reproduced with permission from ref 41 , Copyright 2016 American Chemical Society. (f) The configuration of beads at $\theta=90^{\circ}$ rotation. Reproduced with permission from ref 41, Copyright 2016 American Chemical Society. (g) Detailed illustration of magnetic levitation platform with NdFeB magnets and mirrors being assembled by using PMMA holders. Reproduced with permission from ref 18, Copyright 2015, Proceedings of the National Academy of Sciences USA. (h) Working principles of microfluidic platform in the presence/absence of magnetic field (top). Schematic and prototype of microfluidic channel system (bottom). Reproduced with permission from ref 51, Copyright 2016 John Wiley and Sons. 
(a)

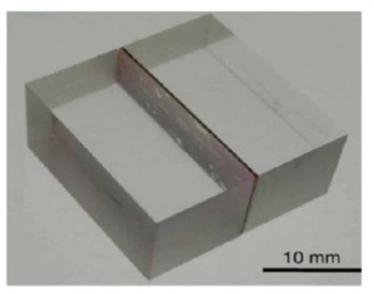

(b)

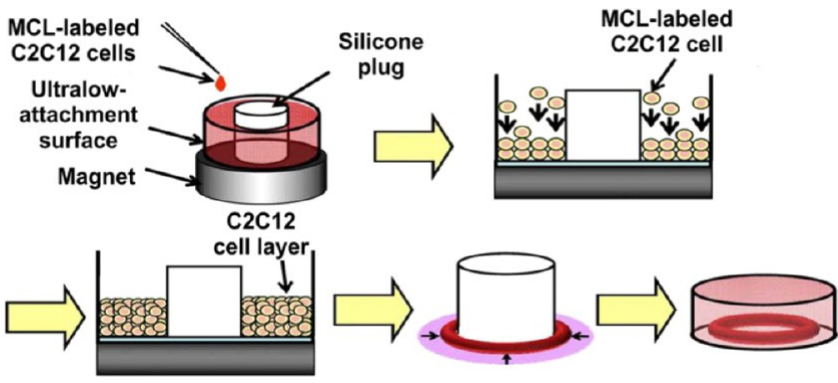

Figure 3. Magnetic levitation setups used for 3D cell culture applications. (a) Basic magnetic field concentrator with a steel plate sandwiched in between acryl resin plates to generate cellular strings. Reproduced with permission from ref 19, Copyright 2009 Elsevier. (b) Schematic illustration for cellular ring construction by Mag-TE technique, where MCL labeled C2C12 cells are seeded into a well where a magnet and a silicon plug are located. Reproduced with permission from ref 19, Copyright 2009 Elsevier.

developed (Figure 2e $)^{41}$ which overcomes the resolution limitations of the previously introduced Tilted MagLev setup. ${ }^{50}$ The new system was able to evaluate weak magnetic gradients in rotated configuration which enables quantification of density differences less than $10^{-4} \mathrm{~g} / \mathrm{cm}^{3}$ (Figure $2 \mathrm{f}$ ).

Previously, an easy-to-use magnetic levitation device (Figure $2 \mathrm{~g})^{18}$ was developed as a diagnostic tool for separating cells. In this system, two permanent magnets were assembled by utilizing poly(methyl methacrylate) (PMMA) holders, and a glass capillary channel was introduced among the magnets. Mirrors were used in a $45^{\circ}$ slope position to visualize the channel using a microscope that helps to evaluate the height of the cells within the channel. When the cells were injected into the paramagnetic medium, they move from higher to lower magnetic field and align due to their density characteristics. To separate the cells, another magnetic levitation setup was introduced where permanent magnets located close to the microfluidic channels (Figure 2h). ${ }^{51}$ Cells levitated from a laminar flow pathway due to the magnetic buoyancy force. Therefore, a mixture of HeLa and blood cells was separated due to their size and density differences.

The use of magnetic levitation on biological materials has also extended toward the tissue engineering field. The earliest system used for tissue engineering is magnetic force-based tissue engineering (Mag-TE) setup. ${ }^{19}$ In this model, a steel plate was squeezed in between acryl resins to fabricate cell strings (Figure 3a). This steel plate is used as a magnetic field concentrator and placed over a magnet to create a magnetic field gradient. Culture dishes were covered with agarose to create an adhesive culture surface, so string-like $3 \mathrm{D}$ cellular constructs were generated on the surface. Later, a $3 \mathrm{D}$ cell culture device (Figure 3b) was made with a silicone plug that is settled at the center of the well plate. Cells were seeded around the silicon plug while a magnet settled underneath the well and was used to orientate ring-shaped cellular constructs.

Recently, a basic Petri dish was modified as a magnetic levitation setup for 3D cell culture studies (Figure 4a). ${ }^{11}$ The 3D bioassembler consists of magnetic iron oxide (MIO) particles, gold nanoparticles (AuNP), and RGD motif containing M13-phage particles was used to provide hydrogel assembly. Cells incubated with hydrogels to gain magnetic property. Magnetic field-based cell levitation was observed, and cells were levitated at air-medium interface upon external magnetic introduction to the system. Both large magnets ( $12 \mathrm{~mm}$ radii) and small magnets ( $6 \mathrm{~mm}$ radii) have been used to observe the effect of magnetic field strength on $3 \mathrm{D}$ cell culture formation. The resulting cell culture structures reflect the strength of the magnetic field; the large radius magnets have a central minimum, which leads to a ring-shape formation (Figure $4 b$ ); in contrast, the smaller magnets result in intense cellular assembly (Figure 4c). Later, the magnetic field-based cell levitation concept evolved toward a 96-well plate format (Figure 4d). ${ }^{29}$ A magnetic drive settled at top of the plate, where poly-L-lysine cross-linked MIO-based bioinorganic hydrogels were utilized to levitate cells at air-medium interface, so cellular agglomeration occurs while supporting extracellular matrix (ECM) synthesis.

\section{MATERIALS USED IN MAGNETIC LEVITATION}

Two major classes of materials are used for magnetic levitation applications; one of them is a paramagnetic agent that gives magnetic property to the medium and ensures diamagnetic objects will levitate, and the other one is scaffold-forming materials (polymers, hydrogels, etc.) that are particularly used as a support material to levitate objects.

$\mathrm{GdCl}_{3}$, copper sulfate $\left(\mathrm{CuSO}_{4}\right)$, holmium chloride $\left(\mathrm{HoCl}_{3}\right)$, ferrous chloride $\left(\mathrm{FeCl}_{2}\right), \mathrm{MnCl}_{2}$, and manganese bromide $\left(\mathrm{MnBr}_{2}\right)$ are some of the paramagnetic agents used in aqueous solutions. ${ }^{36}$ Each of these paramagnetic salts has different magnetic susceptibilities, which leads to differentiation of the densities of objects. Thus, these materials are used as a paramagnetic agent to manipulate the objects in aqueous solution. The previously mentioned study ${ }^{36}$ examined solids and waterimmiscible organic liquids between $1.0-1.7 \mathrm{~g} / \mathrm{cm}^{3}$ density range by using $\mathrm{GdCl}_{3}$ and $\mathrm{MnCl}_{2}$ in water. Depending on the type of paramagnetic salt, the density range can be adjusted. Alcohol or other organic solvents can solvate $\mathrm{Gd}^{3+}$ and $\mathrm{Mn}^{2+}$ salts and increase the density range to $0.8-3.0 \mathrm{~g} / \mathrm{cm}^{3}$. Besides different gadolinium salts, other paramagnetic agents that are magnetic resonance imaging (MRI) contrast agents used for clinical investigation such as gadobutrol and gadoteric acid have been used for magnetic levitation applications. Particularly with respect to cell-based studies, ${ }^{18}$ these paramagnetic agents show low toxicity compared to that of other counterparts.

Gel-forming materials aid the levitation of biological materials. In 3D cell culture studies, bioinorganic hydrogels have been used with MIOs. ${ }^{11}$ The combination of hydrogel with MIO particles provides magnetic manipulation of cells while culturing them at the same time (Figure $4 \mathrm{a}$ ). Additionally, polymer-based hydrogels such as methacrylated gelatin (GelMA) and polyethylene glycol dimethacrylate (PEGDA) ${ }^{27}$ are commonly used examples for microgel production, and cells are seeded or encapsulated into these soft materials to levitate them in paramagnetic solutions. Those living soft materials can be assembled into more complex 3D structures via magnetic levitation. 
(a)

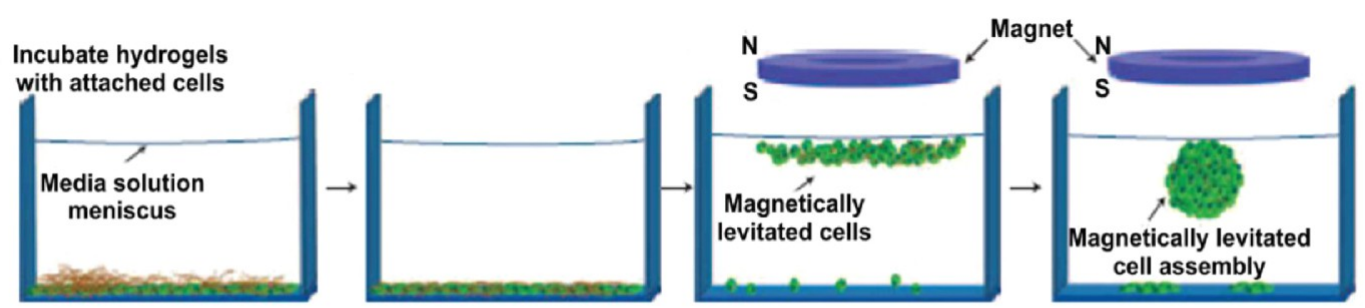

(b)
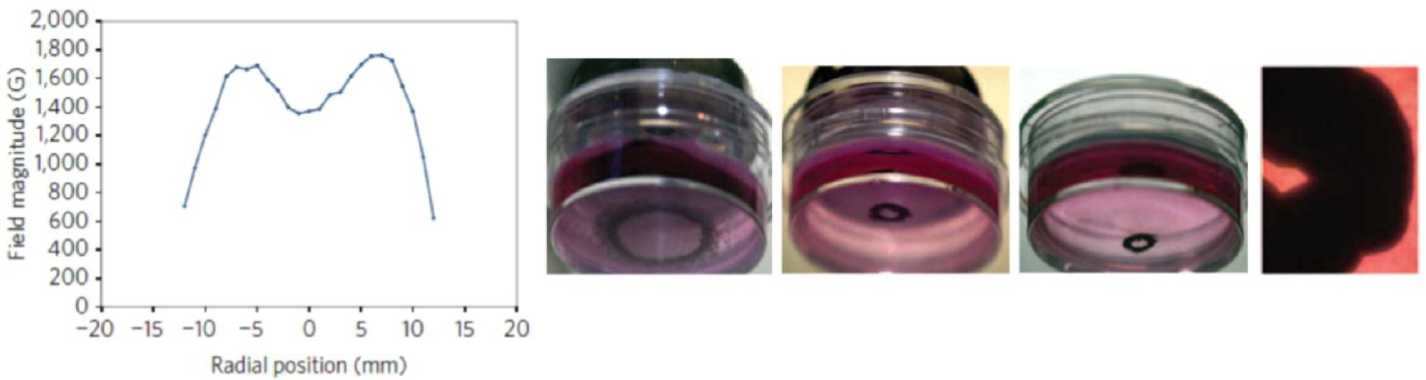

(c)
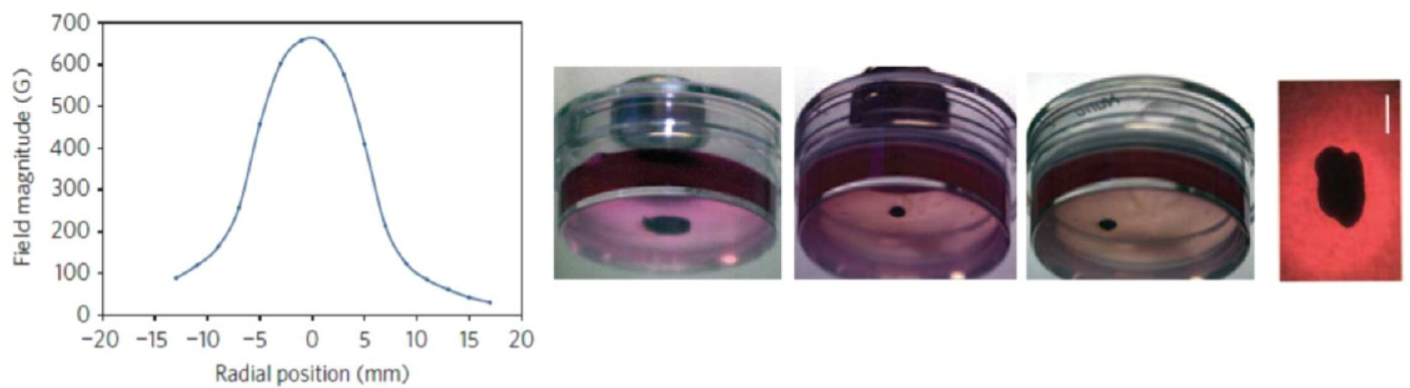

(d)
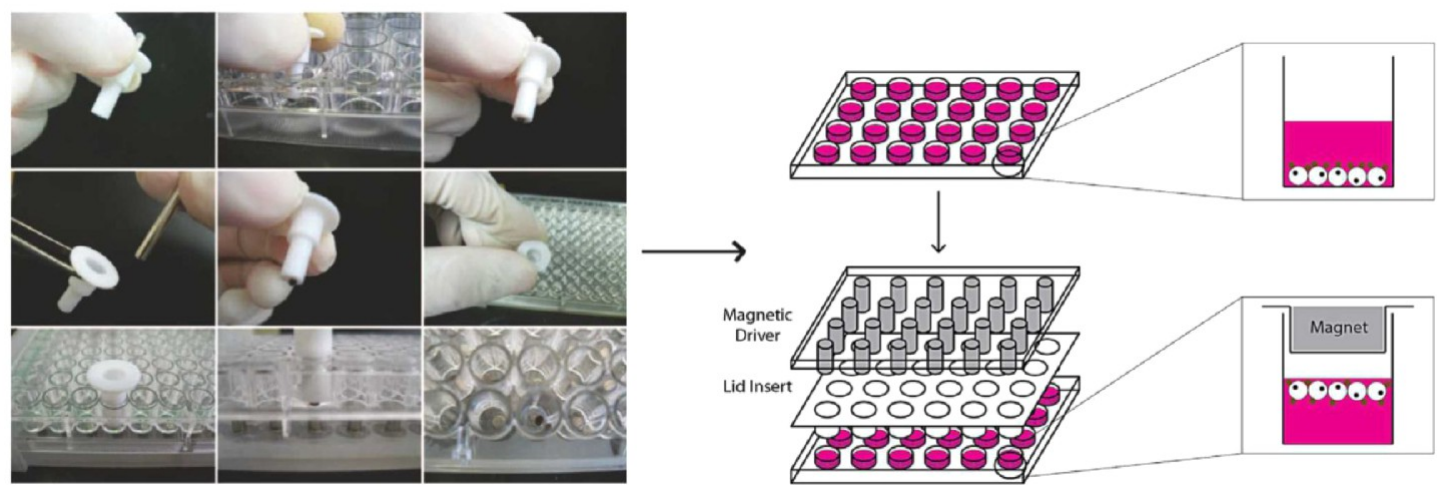

Figure 4. Magnetic levitation setups used for 3D cell culture. (a) Illustration of magnetic levitation setup for 3D cell culture; MIO containing hydrogels are added over the cells, and then a magnetic force is applied to raise cells to the air-medium interface. Reproduced with permission from ref 11, Copyright 2010 Nature. (b and c) 3D shape control of levitated cells by using (b) 12 and (c) 6 mm magnets. Reproduced with permission from ref 11, Copyright 2010 Nature. (d) A well-plate form of magnetic levitation setup for 3D cell culture. Transfer of 3D cell culture from 24-well plate to 96-well plate by using a Teflon pen. After removal of the magnet from the pen, 3D cell culture settled into the 96-well plate. Reproduced with permission from ref 22, Copyright 2014 Elsevier. Reproduced with permission from ref 29, Copyright 2013 Nature.

\section{STATE-OF-THE-ART MAGNETIC LEVITATION}

Magnetic levitation holds a great promise to revolutionize the current understanding in bioanalytical science by providing a novel toolbox for the contactless manipulation of biological substances. ${ }^{1,10,11,27,53}$ Recent approaches that use magnetic levitation can be divided into three subcategories: (i) 3D selfassembly, (ii) tissue engineering, and (iii) diagnostic tool applications. In this section, we highlight utilization and development of magnetic levitation in all three subcategories.

5.1. 3D Self-Assembly via Magnetic Levitation. Selfassembly is a process that can produce different functional systems by combining varied microstructures at the same time. ${ }^{10}$ Magnetic force, ${ }^{1,54,55}$ capillary force, ${ }^{56-58}$ electrostatic force, ${ }^{59,60}$ surface energy, ${ }^{61-63}$ and gravity-based methods ${ }^{64,65}$ are some of the basic technologies of self-assembly that have been introduced for various applications.

Magnetic force has a multifunctional ability for guiding 3D self-assembly processes. ${ }^{24}$ The utilization of magnetic interactions for 3D self-assembly is highly convenient method because objects are exposed to the magnetic force from a certain distance; thus, no physical contact is required. Recently, magnetic levitation principle has been applied to varied systems for 3D selfassembly of diamagnetic objects without any magnetic 
(a)

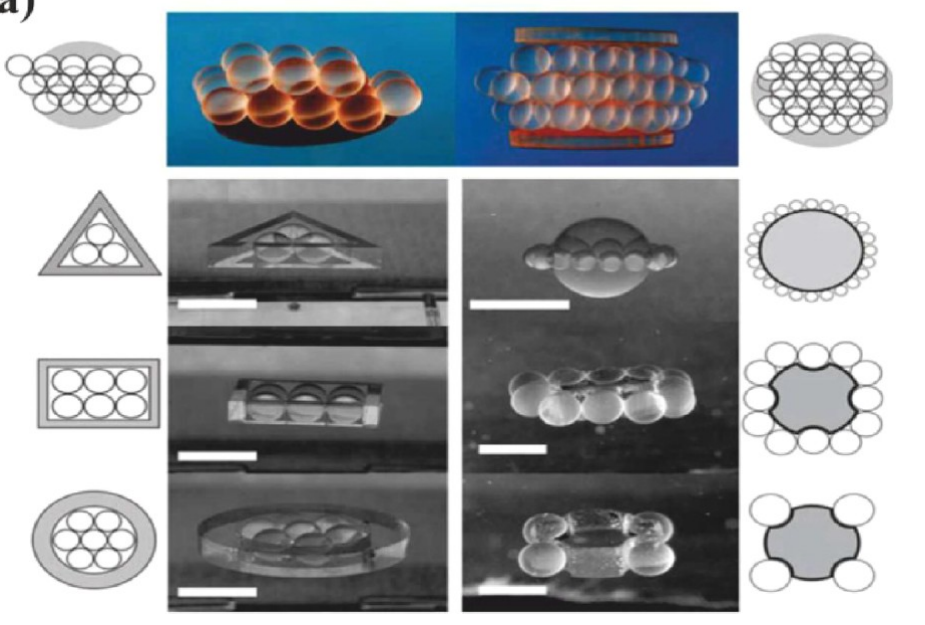

(b)

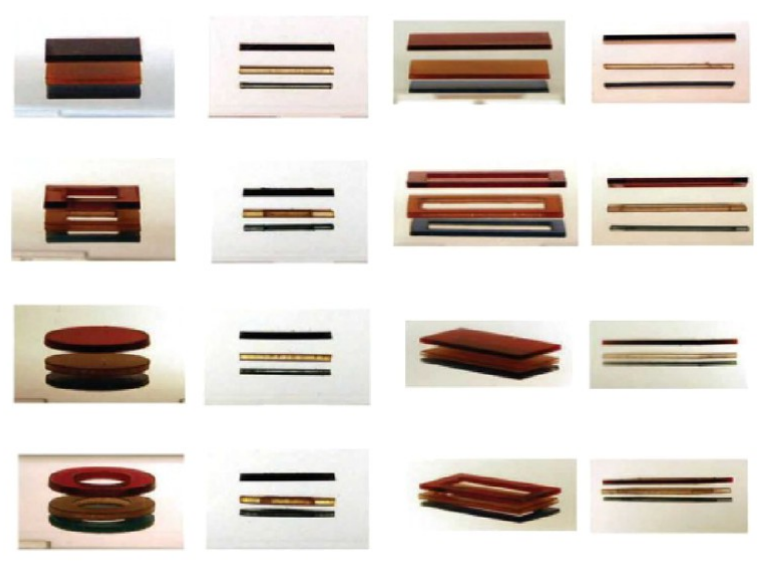

Figure 5. 3D assembly of polymeric materials via magnetic levitation method. (a) 3D assembly of PMMA spheres (top) accompanied by colevitating PMMA templates (middle and bottom). Reproduced with permission from ref 23, Copyright 2011 Royal Society of Chemistry. (b) PMMA and PVC templates levitate according to their density differences. Reproduced with permission from ref 24, Copyright 2011 John Wiley and Sons.

Table 1. Summary of Magnetic Levitation-Based Tissue Engineering Applications

\begin{tabular}{|c|c|c|c|}
\hline materials/methods & application & cell type & ref \\
\hline magnetite cationic liposomes (MCLs) & artificial muscle tissue engineering & $\mathrm{C} 2 \mathrm{C} 12$ & 19 \\
\hline \multirow{3}{*}{$\begin{array}{l}\text { M13 derived MIO/magnetic field-based cell } \\
\text { levitation }\end{array}$} & \multirow[t]{3}{*}{ multicellular coculture } & LN-229 & \multirow[t]{3}{*}{11} \\
\hline & & U-215MG & \\
\hline & & $\mathrm{C} 17.2$ & \\
\hline $\begin{array}{l}\text { MIO hydrogel (NanoShuttle)/magnetic field-based } \\
\text { cell levitation }\end{array}$ & $3 \mathrm{D}$ cell culture & $\begin{array}{l}\text { HEK293, MDA 231, MCF-10A, LNCaP, A549, } \\
\text { HepG2, 3T3-L1, bEnd.3, H-4-II-E, U251-MG }\end{array}$ & 29 \\
\hline \multirow{2}{*}{$\begin{array}{l}\text { MIO hydrogel (NanoShuttle)/magnetic field-based } \\
\text { cell levitation }\end{array}$} & adipose tissue engineering & $3 \mathrm{~T} 3-\mathrm{L} 1$ & \multirow[t]{2}{*}{20} \\
\hline & white adipose tissue-based cell therapy & bEnd.3 & \\
\hline \multirow{4}{*}{$\begin{array}{l}\text { MIO hydrogel (NanoShuttle)/magnetically } \\
\text { levitated four cell coculture }\end{array}$} & bronchiole coculture & EpiCs & \multirow[t]{4}{*}{21} \\
\hline & inflammatory response angiogenesis & SMCs & \\
\hline & air way remodeling research & PFs & \\
\hline & & PECs & \\
\hline \multirow{2}{*}{$\begin{array}{l}\text { MIO hydrogel (NanoShuttle)/magnetic } \\
\text { nanoparticle-based coculture of VIC sand VECs }\end{array}$} & \multirow[t]{2}{*}{ heart valve engineering } & VICs & \multirow[t]{2}{*}{22} \\
\hline & & VECs & \\
\hline \multirow{6}{*}{$\begin{array}{l}\text { MIO hydrogel (NanoShuttle)/magnetically } \\
\text { levitated breast tumor model }\end{array}$} & understanding of tumor biology & $\mathrm{HPF}$ & \multirow[t]{6}{*}{30} \\
\hline & drug screening & SUM 159 & \\
\hline & & MDA-MB-231 & \\
\hline & & Hs785bst & \\
\hline & & Hs371.t & \\
\hline & & $293 \mathrm{~T}$ & \\
\hline
\end{tabular}

moments and unpaired electrons being balanced by gravitational and magnetic forces. An example of this contactless manipulation approach has been focused on formation and packing of complex 3D structures via magnetically levitated spherical and nonspherical objects (Figure 5a). ${ }^{23}$

The way in which shape and density of PMMA templates affect the formation of complex 3D models has been investigated. The design of a colevitating PMMA template ensures that spherical PMMA objects form alternative 3D lattices and structures. As represented in Figure 5a, colevitating templates provide a framework for the levitating objects to form an ordered structure; otherwise, objects go into disordered positions without forming clusters. Depending on colevitating PMMA templates, various forms of lattices and structures can be obtained. Different shaped frames (e.g., rectangular, triangular, and circular) that have the same density with objects allow packing of the objects into the frame in 3D. Alternatively, levitating objects can surround the surfaces or edges of the colevitating templates
(Figure 5a). In another study, diamagnetic objects were guided through the magnetic field that generates 3D assemblies depending on density difference. Figure $5 b^{24}$ shows the formation of 3D assemblies for both PMMA and polyvinyl chloride (PVC) levitating templates, which is guided by the magnetic field of the bottom magnet. Magnetic levitation technology ${ }^{36,43}$ ensures formation of $3 \mathrm{D}$ structures by aligning, positioning, and selfassembling components without any physical handling. Consequently, development of magnetic levitation and contactless manipulation contributes to development of other fields such as tissue engineering and diagnostic tools.

5.2. Current Tissue Engineering Strategies. Magnetic levitation technology has recently been used to demonstrate the ability of the technique for culturing cells in a 3D microenvironment. ${ }^{2,66-68}$ Although there are other approaches such as bioreactors, ${ }^{69-72}$ microfluidics, ${ }^{73-77}$ stereolithography, ${ }^{78-81}$ etc. for tissue engineering, most of these focus on the development of materials. Rather than developing new materials, 
tissue engineering needs innovative methodologies to create $3 \mathrm{D}$ cellular structures by mimicking the natural microenvironment. $^{2}$ In addition, it also requires cell-cell and cellECM interactions so that tissues can become functional.
Considerable effort is being targeted at developing functional tissues; however, guiding cells into a desired complex 3D structure and forming the physical force environment is still an obstacle that needs to be overcome. To cope with those (a)

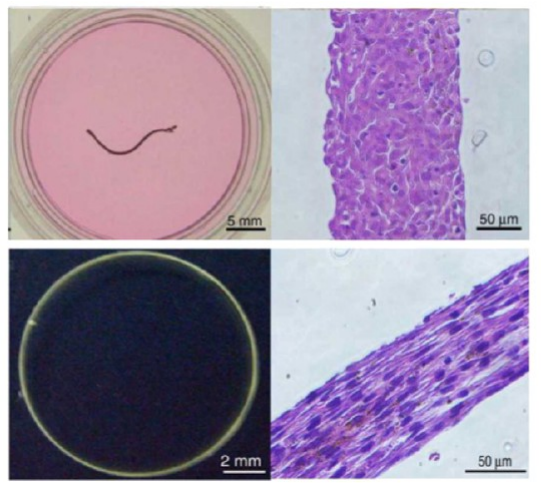

(b)

$2 \times 10^{6}$ cells/well

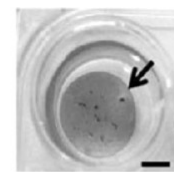

$4 \times 10^{6}$ cells/well

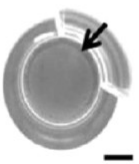

$4 \mathrm{~h}$

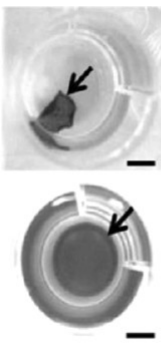

$12 \mathrm{~h}$

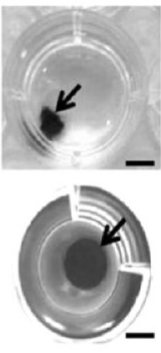

$24 \mathrm{~h}$
Figure 6. Mag-TE technique. (a) C2C12 cell string (above) and cell ring (below) constructs and bright-field micrographs of hematoxylin and easinstained longitudinal section of the cellular string and ring. Reproduced with permission from ref 19, Copyright 2009 Elsevier. (b) The shrinkage of C2C12 cell sheets (indicated by arrows) in different culture periods. Reproduced with permission from ref 19, Copyright 2009 Elsevier. (a)
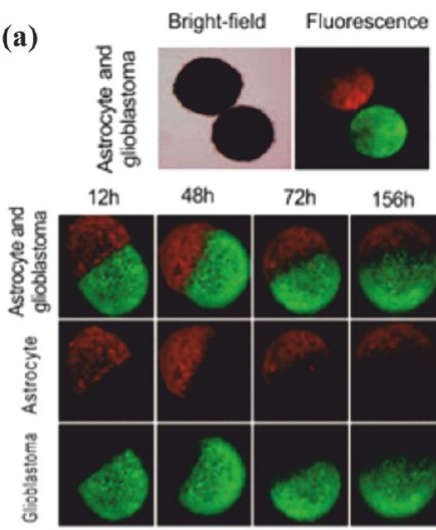

$12 \mathrm{~h} \quad 48 \mathrm{~h}$

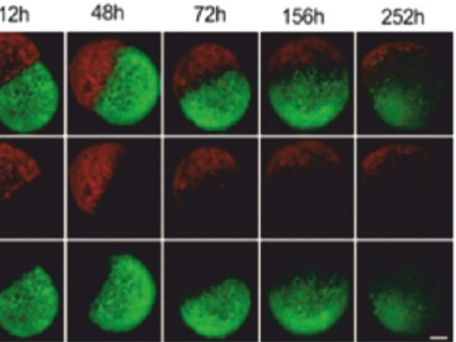

(c)

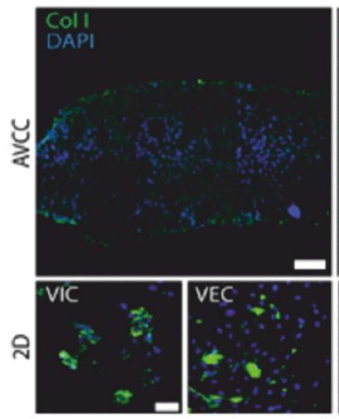

(d)

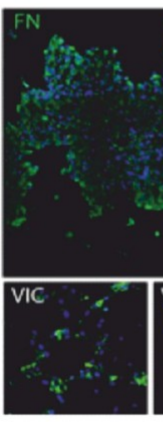

MDA-MB231

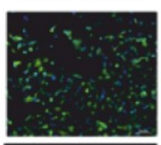

3D
SUM159

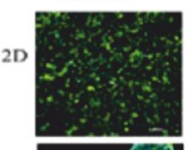

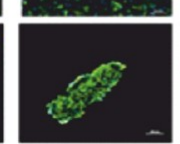

(b)
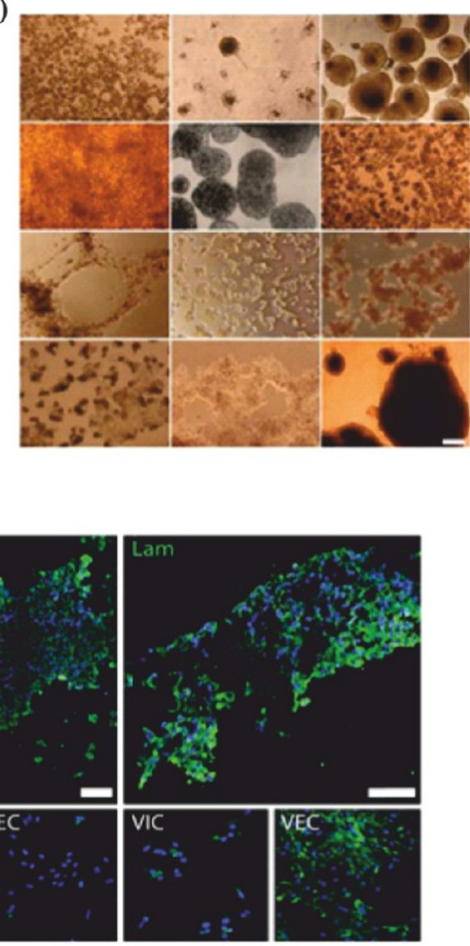

Hs578b

293T
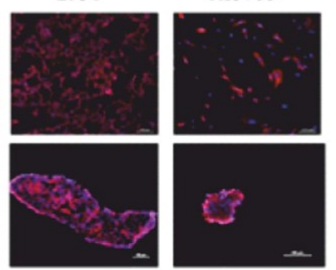

Figure 7. 3D cell culture by magnetic levitation. (a) Spheroid fusion of human glioblastoma cells (green) and normal astrocytes (red) shown by bright-field and fluorescence microscopy. Reproduced with permission from ref 11, Copyright 2010 Nature. (b) Micrograph images of magnetically levitated 3D cell cultures for varied cell types (HEK293, human tracheal smooth muscle cells, human pulmonary fibroblasts, human glioblastoma, H-4-II-E, MDA-231, HUVECs, MCF-10A, LNCaP, HepG2, A549, and 3T3-L1), scale bar $100 \mu$ m. Reproduced with permission from ref 29, Copyright 2013 Nature. (c) Col I, FN, Lam staining in 3D AVCC (aortic valve coculture) and 2D VICs and VECs) cell cultures; IHC stain (green) and nuclei are counterstained with DAPI (blue). Reproduced with permission from ref 22, Copyright 2014 Elsevier. (d) Immunostaining patterns in $2 \mathrm{D}$ and $3 \mathrm{D}$ models of fibroblast cell and breast cancer cells in three days in 3D model cells forming a tumor structure with heterogeneous cell distribution. Reproduced with permission from ref 30, Copyright 2014 Nature. 
(a)
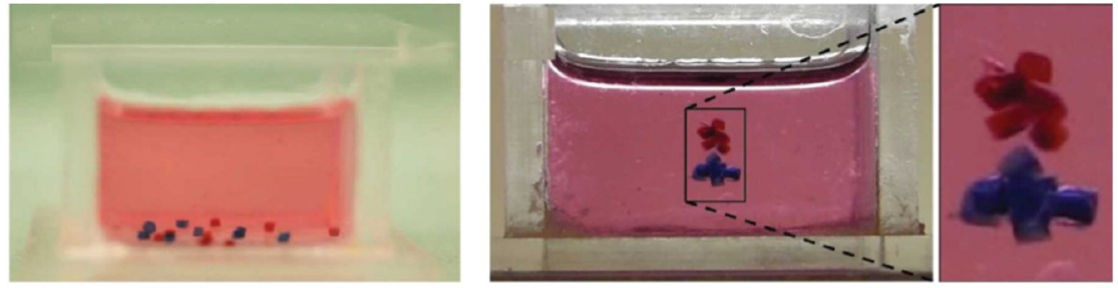

(b) Day 0 - MagLev cell culture

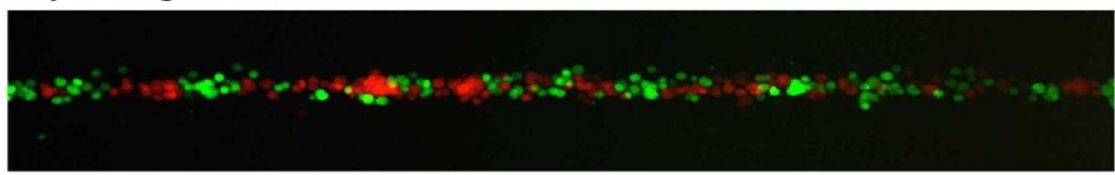

Day 5 - MagLev cell culture

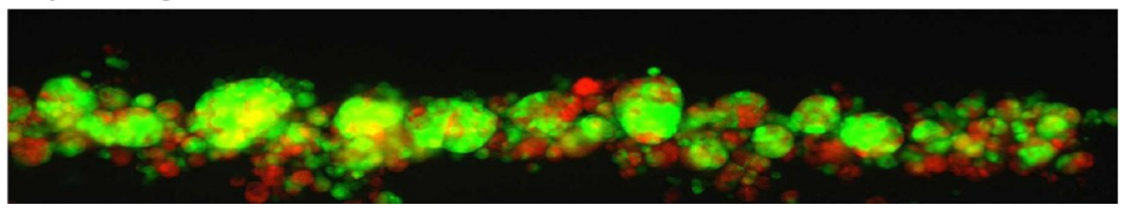

Figure 8. Magnetic levitation-based tissue engineering approaches. (a) Selective levitational assembly of PEG hydrogels. Red and blue hydrogels formed assemblies at different levels due to their polymer concentration. Reproduced with permission from ref 27, Copyright 2015 John Wiley and Sons. (b) Scaffold-free 3D cell culture via magnetic levitation.

difficulties, magnetic levitation offers a contactless manipulation option while preserving the natural microenvironment of the cells.

Magnetic levitation-based tissue engineering systems have different applications in varied fields such as drug discovery, ${ }^{30}$ regenerative medicine, ${ }^{19,21,22}$ stem-cell research, and tumor biology. ${ }^{11}$ Current efforts on magnetic levitation-based tissue engineering are summarized in Table 1.

Recently, a magnetic force-based tissue-engineering technique; Mag-TE (Figures $3 a$ and $b$ ) has been reported for the formation of artificial skeletal muscle tissue. ${ }^{19}$ Here, generating string or ring-shaped tissue structures mimicked the fiber bundles of skeletal muscle. Magnetite cationic liposomes (MCLs) were employed as a magnetic agent, and MCL uptake by Myoblast C2C12 cells was completed prior to application of magnetic force. Seeding $\mathrm{C} 2 \mathrm{C} 12$ cells onto a magnetic concentrator where a magnet is located underneath, both cell strings and cell rings (Figure 6a) were obtained via agglomeration without any scaffold. Cell sheets and cell strings were obtained in desired shape and thickness (around $200 \mu \mathrm{m}$ ); however, they shrank and lost their shapes during further culture periods for myogenic differentiation (Figure 6b).

In another study, M13 phage-based bioinorganic hydrogel system with magnetic properties (Figure 4a) was introduced to mimic irregular tumor formation by coculturing. ${ }^{11}$ This study offers a controlled system, which shows formation of $3 \mathrm{D}$ in vitro tumor structures at varied size and composition. Not only $3 \mathrm{D}$ cell culture formation but also spheroid fusion is controlled by this model system. To demonstrate the ability of the introduced technique for magnetic manipulation, both human glioblastoma cell spheroids and human astrocyte cell spheroids were magnetically guided together, with spheroid fusion being obtained in $12 \mathrm{~h}$ (Figure 7a). The introduced magnetic levitation system is further extended to a highly sophisticated wellplate format (Figure 4d) for easier and more controlled tissue formation. ${ }^{29}$ Poly-L-lysine cross-linked MIO/AuNP hydrogels named as NanoShuttle (Nano3D Biosciences, United States) were utilized as a magnetizing agent for $3 \mathrm{D}$ cell culture formation. 3D cell culture forming ability of this straightforward magnetic levitation technique was demonstrated by using different cell lines such as human embryonic kidney cells (HEK293), mouse fibroblast cells (3T3-L1), human mammary epithelial (MDA-231), human umbilical vein endothelial cell (HUVECs), and human hepatocyte cell (HepG2). 3D cell culture formation was obtained for all varied cell lines (Figure $7 b$ ); based on the cellular characteristics, some formed denser and smaller structures, while others formed less dense and sparse structures. The developed magnetic levitation method for $3 \mathrm{D}$ cell culture was further used for the formation and investigation of adipose tissue, ${ }^{20}$ a coculture of bronchiole, ${ }^{21}$ a breast tumor model, ${ }^{30}$ and also to create a coculture of $3 \mathrm{D}$ aortic valve. ${ }^{22}$ White adipose tissue (WAT) formation ${ }^{20}$ was achieved through a combination and aggregation of adipose cells to produce organoids termed adipospheres.

Later, coculture of a bronchiole ${ }^{21}$ in vitro model was obtained through assembly of human pulmonary microvascular endothelial cells (PECs), human pulmonary fibroblasts (PFs), human bronchial epithelial cells (EpiCs), and human tracheal smooth muscle cells (SMCs). After those achievements, utilization of the developed magnetic levitation method was extended to 3D aortic valve assembly ${ }^{22}$ (Figure $7 \mathrm{c}$ ) and breast tumor model ${ }^{30}$ (Figure $7 \mathrm{~d}$ ) formation.

Quite recently, the magnetic manipulation of living objects in a paramagnetic salt solution was demonstrated for tissue engineering applications. ${ }^{27} \mathrm{NIH} 3 \mathrm{~T} 3$ mouse fibroblast cells were encapsulated either in GelMA or PEGDA hydrogels. To paramagnetize the suspension solution, paramagnetic $\mathrm{Gd}^{3+}$ salt was utilized. Self-assembly of cell encapsulated microstructures was achieved through magnetic levitation technique (Figure 8a).

However, the above-mentioned magnetic levitation techniques employ scaffolds or other support materials. For tissue engineering or regenerative medicine applications, material dependency is an important limiting factor. To overcome this limitation, a new technique was developed which utilizes magnetic levitation methodology for 3D cell culture in scaffold-free format (Figure $8 \mathrm{~b})^{82}$ which promotes cells to secrete their own ECM without any additional materials to form 3D structure. Progress in this technology enables mimicking of tissue models 
more closely while maintaining the natural microenvironment and native ECM molecules.

5.3. Current Diagnostic Strategies. Miniaturized diagnostic devices are mostly preferred these days because of their rapid, cheap, portable, easy-to-use properties for identifying diseases or informing people rapidly about their state of health. ${ }^{13,83-86}$ Current diagnostic tools generally rely on immunospecific interactions to separate and acquire targets from complex media that complicate detection processes in terms of cost effectiveness, durability and time of analysis. Magnetic levitation has emerged in recent years with the aim of analyzing and characterizing biological macromolecules by its potential to overcome these obstacles. A comparison of the most commonly used magnetic levitation-based diagnostic models are introduced in Table 2.

In recent years, magnetic levitation setup was developed to measure protein-ligand interactions, ${ }^{16,17}$ in which BCA and derivatives of benzenesulfonamide act as a protein and ligand, respectively. The beads were functionalized with ligands, so proteins are bound to the latter and lead to a change in density of the bead. Depending on levitation height, (i) amount of a bound protein and (ii) association and dissociation of a protein can be measured (Figure 9a). ${ }^{16}$ It is concluded that this method can be efficiently used for the analysis of varied biological molecules and biomarkers for diagnostic purposes. The magnetic levitation approach was further extended to metalamplified density assay of varied biomolecules such as proteins, antigens, and nucleic acids (Figure $9 \mathrm{~b}$ ), ${ }^{87}$ and being particularly linked with ELISA and termed a density-linked immunosorbent assay (DeLISA). The performance of the system as a diagnostic tool was evaluated successfully via multiplexed detection of NS3 protein of Hepatitis C (Hep C) virus and p47 protein of syphilis Treponema pallidum in serum samples (Figure 9c).

Current studies on magnetic levitation offer rapid separation of single cells or cell populations, depending on their unique density or magnetic properties. A simple magnetic levitation platform (Figure 2g) was introduced recently for separation of single cells. ${ }^{18}$ This method is a density-based technique which enables quick and easy profiling of cells. Here, the magnetic levitation is applied to breast, esophageal, nonsmall cell lung cancer, and colorectal cancer cell lines, and as a result, characteristic blueprints were obtained due to density differences (Figure 9d).

A similar setup was integrated into a smartphone for cell (i-LEV) and microparticle analysis. ${ }^{85,88}$ Both systems included a lens for focusing images on the camera; a magnetic levitation setup with capillaries settled below the lens to observe the height of levitated cells or particles. Both the cells (Figure 9e) and microparticles (Figure 9f) were separated depending on their density characteristics. Utilization of such systems confirmed that the magnetic levitation methodology has high potential for bioanalysis applications especially as a miniaturized diagnostic tool in resource-limited settings.

In another study, the above-mentioned magnetic field-based cell levitation technique ${ }^{29}$ that utilizes NanoShuttle for 3D cell culture formation was used for diagnostic applications, especially in toxicity assays. While cells treated with NanoShuttle, they acquire magnetic properties and are easily guided under magnetic field. When a magnetic field is applied, cells are levitated and then either collected or printed at the bottom of the plate to form 3D cell structures. The whole assay was imaged with a mobile device that decreases imaging time compared to microscopes and enhances efficiency of drug toxicity

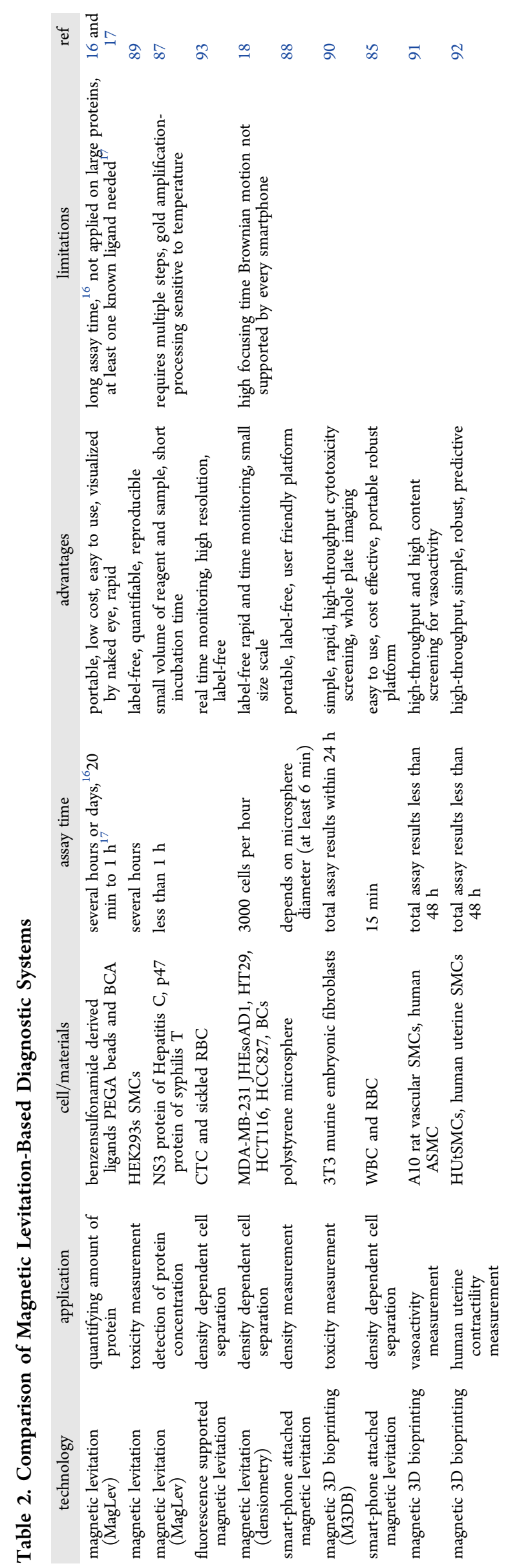


(a)

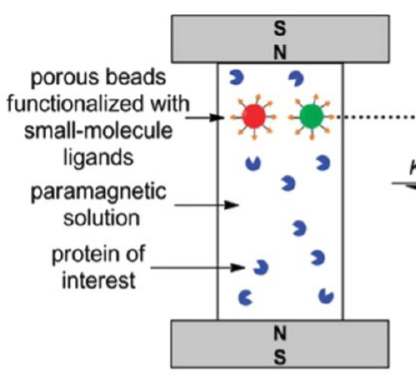

(b)

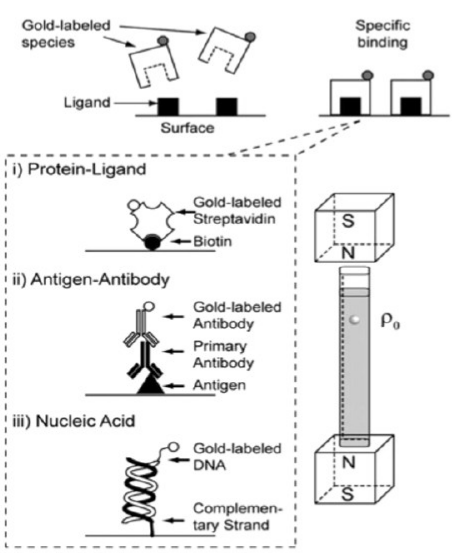

(c)

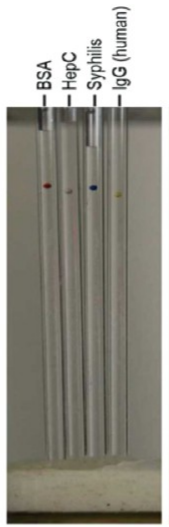

Beads at
$\mathrm{t}=0$

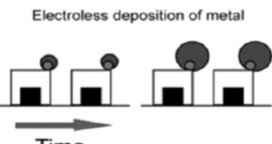

Time
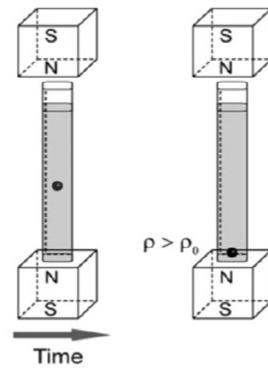

(f)

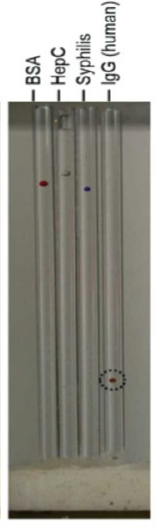

Sample 1 HepC Syphilis

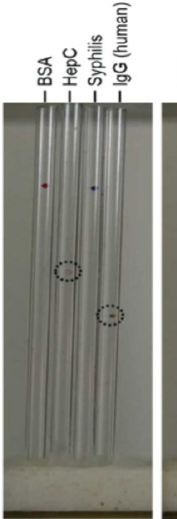

Sample 2 HepC + Sample 3 Syphilis - Syphilis
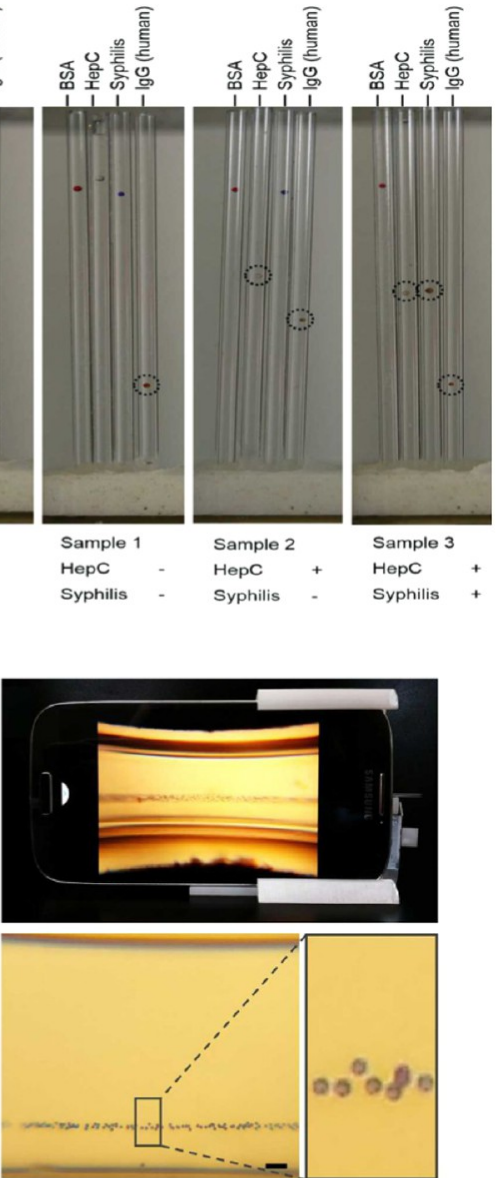

(d)

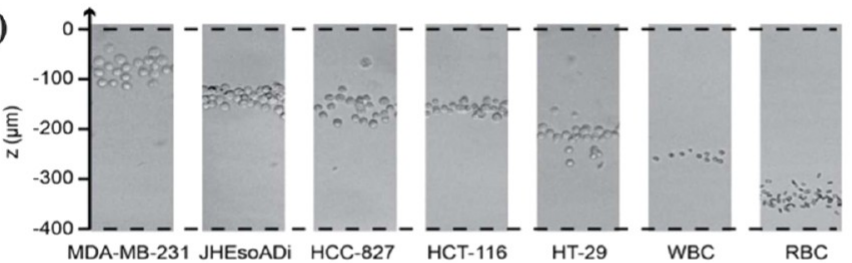

(e)

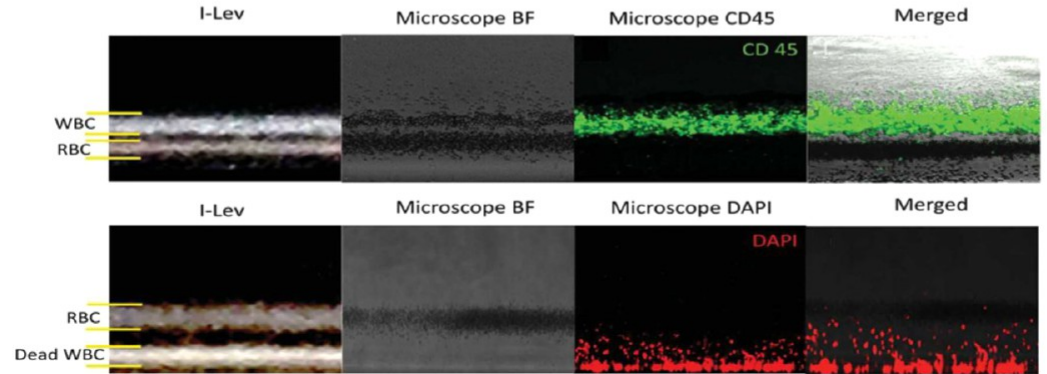

Figure 9. Magnetic levitation-based diagnostic and biosensor applications. (a) Polymeric gel beads functionalized with small ligands to bind the target protein, so the density of the bead changes and starts to levitate with protein binding. Reproduced with permission from ref 16 , Copyright 2012 American Chemical Society. (b) Schematic representation of metal-amplified density assays (MADAs). Reproduced with permission from ref 87, Copyright 2015 Royal Society of Chemistry. (c) Multiplexed immunoassay for syphilis and Hepatitis C via magnetic levitation. The first column represents the beads after settling in developing buffer; second column represents negative results for both syphilis and Hep C; and the third column represents positive for Hep C. The fourth column represents positive results for syphilis and Hep C. Reproduced with permission from ref 87, Copyright 2015 Royal Society of Chemistry. (d) Magnetically levitated cancer and blood cells via density-based cell separation, (HCC827, nonsmall cell lung adenocarcinoma cells; HCT116, colorectal carcinoma cells; HT29, colorectal adenocarcinoma cells; JHEsoAD1, esophageal adenocarcinoma cells; MDA-MB-231, breast adenocarcinoma cells). Reproduced with permission from ref 18, Copyright 2015 Proceedings of the National Academy of Sciences USA. (e) Red and white blood cell separation within i-LEV platform (top) and live/dead assay imaging (bottom) of cells. Reproduced with permission from ref 85, Copyright 2016 John Wiley and Sons. (f) Smartphone-attached magnetic levitation platform where microparticles are levitated depending on their densities. A smartphone camera and 3D printed attachment are used to capture polystyrene microsphere $(10 \mu \mathrm{m})$ images, scale bar is $100 \mu \mathrm{m}$. Reproduced with permission from ref 88, Copyright 2015 PLOS ONE. 
screening. This method was improved for toxicity screening of 3D cellular structures. ${ }^{89}$ Afterward, this method evolved to magnetic 3D bioprinting (M3DB) where 3D cell structures were formed to measure cytotoxicity, ${ }^{90}$ vasoactivity, ${ }^{91}$ and uterine contractility measurements. ${ }^{92}$

\section{CONCLUSION AND FUTURE PERSPECTIVE}

This review aimed to provide a broad perspective and overview of the current advances and applications of magnetic levitation in biotechnology. We also attempted to consolidate critical studies using current magnetic manipulation methodologies contributing to the field of diagnostics as well as tissue engineering. The advancements in separation, classification, and manipulation of living cells confirm the potential of magnetic levitation methodologies in diagnostics and tissue engineering fields. Recently, considerable efforts have been devoted to developing novel magnetic levitation platforms that facilitate guiding of living cells to generate hierarchically ordered tissues. Magnetic levitation technology also enables contactless capturing and separation of diagnostic biomarkers from complex media such as blood, plasma, and other body fluids that reduces the tedious sample pretreatment time and efforts. These advancements will pave the way to rationalization of wearable, implantable continuous monitoring lab-on-a-chip systems that are robust and resistant to interference. In addition, advancements in contactless manipulation will foster developments in functional artificial tissue formation. The future challenges in biotechnology demand novel technologies and new generation biomaterials converging to perfection that minimizes drawbacks. Magnetic levitation has emerged as a versatile tool for controlling spatial order at the single-cell level and contactless manipulation of target bioentities at the cellular level. We foresee that the magnetic levitation will exhibit future potential to generate novel advancements in biotechnology fields.

\section{AUTHOR INFORMATION}

\section{Corresponding Author}

*E-mail: ahuarslan@iyte.edu.tr.

\section{ORCID 1}

Ahu Arslan-Yildiz: 0000-0003-0348-0575

Notes

The authors declare no competing financial interest.

\section{REFERENCES}

(1) Tasoglu, S.; Kavaz, D.; Gurkan, U. A.; Guven, S.; Chen, P.; Zheng, R.; Demirci, U. Paramagnetic levitational assembly of hydrogels. Adv. Mater. 2013, 25 (8), 1137-43.

(2) Grogan, S. P.; Pauli, C.; Chen, P.; Du, J.; Chung, C. B.; Kong, S. D.; Colwell, C. W.; Lotz, M. K.; Jin, S.; D’Lima, D. D. In situ tissue engineering using magnetically guided three-dimensional cell patterning. Tissue Eng Part C Methods. Tissue Eng., Part C 2012, 18 (7), 496-506.

(3) Tasoglu, S.; Gurkan, U. A.; Wang, S.; Demirci, U. Manipulating biological agents and cells in micro-scale volumes for applications in medicine. Chem. Soc. Rev. 2013, 42 (13), 5788-808.

(4) Xu, F.; Finley, T. D.; Turkaydin, M.; Sung, Y.; Gurkan, U. A.; Yavuz, A. S.; Guldiken, R. O.; Demirci, U. The assembly of cellencapsulating microscale hydrogels using acoustic waves. Biomaterials 2011, 32 (31), 7847-55.

(5) Ding, X.; Lin, S. C.; Kiraly, B.; Yue, H.; Li, S.; Chiang, I. K.; Shi, J.; Benkovic, S. J.; Huang, T. J. On-chip manipulation of single microparticles, cells, and organisms using surface acoustic waves. Proc. Natl. Acad. Sci. U. S. A. 2012, 109 (28), 11105-9.
(6) Li, H.; Friend, J. R; Yeo, L. Y. A scaffold cell seeding method driven by surface acoustic waves. Biomaterials 2007, 28 (28), 4098104.

(7) Laurell, T.; Petersson, F.; Nilsson, A. Chip integrated strategies for acoustic separation and manipulation of cells and particles. Chem. Soc. Rev. 2007, 36 (3), 492-506.

(8) Nilsson, J.; Evander, M.; Hammarstrom, B.; Laurell, T. Review of cell and particle trapping in microfluidic systems. Anal. Chim. Acta 2009, 649 (2), 141-57.

(9) Demirci, U.; Montesano, G. Single cell epitaxy by acoustic picolitre droplets. Lab Chip 2007, 7 (9), 1139-1145.

(10) Tasoglu, S.; Yu, C. H.; Gungordu, H. I.; Guven, S.; Vural, T.; Demirci, U. Guided and magnetic self-assembly of tunable magnetoceptive gels. Nat. Commun. 2014, 5, 4702.

(11) Souza, G. R.; Molina, J. R.; Raphael, R. M.; Ozawa, M. G.; Stark, D. J.; Levin, C. S.; Bronk, L. F.; Ananta, J. S.; Mandelin, J.; Georgescu, M. M.; Bankson, J. A.; Gelovani, J. G.; Killian, T. C.; Arap, W.; Pasqualini, R. Three-dimensional tissue culture based on magnetic cell levitation. Nat. Nanotechnol. 2010, 5 (4), 291-6.

(12) Dobson, J. Remote control of cellular behaviour with magnetic nanoparticles. Nat. Nanotechnol. 2008, 3 (3), 139-43.

(13) Knowlton, S. M.; Sencan, I.; Aytar, Y.; Khoory, J.; Heeney, M. M.; Ghiran, I. C.; Tasoglu, S. Sickle cell detection using a smartphone. Sci. Rep. 2015, 5, 15022.

(14) Valles, J. M.; Lin, K.; Denegre, J. M.; Mowry, K. L. Stable magnetic field gradient levitation of Xenopus laevis: toward low-gravity simulation. Biophys. J. 1997, 73 (2), 1130-1133.

(15) Guevorkian, K.; Valles, J. M., Jr Swimming Paramecium in magnetically simulated enhanced, reduced, and inverted gravity environments. Proc. Natl. Acad. Sci. U. S. A. 2006, 103 (35), 13051-6.

(16) Shapiro, N. D.; Mirica, K. A.; Soh, S.; Phillips, S. T.; Taran, O.; Mace, C. R.; Shevkoplyas, S. S.; Whitesides, G. M. Measuring binding of protein to gel-bound ligands using magnetic levitation. J. Am. Chem. Soc. 2012, 134 (12), 5637-46.

(17) Shapiro, N. D.; Soh, S.; Mirica, K. A.; Whitesides, G. M. Magnetic levitation as a platform for competitive protein-ligand binding assays. Anal. Chem. 2012, 84 (14), 6166-72.

(18) Durmus, N. G.; Tekin, H. C.; Guven, S.; Sridhar, K.; Arslan Yildiz, A.; Calibasi, G.; Ghiran, I.; Davis, R. W.; Steinmetz, L. M.; Demirci, U. Magnetic levitation of single cells. Proc. Natl. Acad. Sci. U. S. A. 2015, 112 (28), E3661-8.

(19) Yamamoto, Y.; Ito, A.; Kato, M.; Kawabe, Y.; Shimizu, K.; Fujita, H.; Nagamori, E.; Kamihira, M. Preparation of artificial skeletal muscle tissues by a magnetic force-based tissue engineering technique. J. Biosci Bioeng 2009, 108 (6), 538-543.

(20) Daquinag, A. C.; Souza, G. R.; Kolonin, M. G. Adipose tissue engineering in three-dimensional levitation tissue culture system based on magnetic nanoparticles. Tissue Eng., Part C 2013, 19 (5), 336-44.

(21) Tseng, H.; Gage, J. A.; Raphael, R. M.; Moore, R. H.; Killian, T. C.; Grande-Allen, K. J.; Souza, G. R. Assembly of a three-dimensional multitype bronchiole coculture model using magnetic levitation. Tissue Eng., Part C 2013, 19 (9), 665-75.

(22) Tseng, H.; Balaoing, L. R.; Grigoryan, B.; Raphael, R. M.; Killian, T. C.; Souza, G. R.; Grande-Allen, K. J. A three-dimensional co-culture model of the aortic valve using magnetic levitation. Acta Biomater. 2014, 10 (1), 173-82.

(23) Ilievski, F.; Mirica, K. A.; Ellerbee, A. K.; Whitesides, G. M. Templated self-assembly in three dimensions using magnetic levitation. Soft Matter 2011, 7 (19), 9113-9118.

(24) Mirica, K. A.; Ilievski, F.; Ellerbee, A. K.; Shevkoplyas, S. S.; Whitesides, G. M. Using magnetic levitation for three dimensional selfassembly. Adv. Mater. 2011, 23 (36), 4134-40.

(25) Subramaniam, A. B.; Yang, D.; Yu, H. D.; Nemiroski, A.; Tricard, S.; Ellerbee, A. K.; Soh, S.; Whitesides, G. M. Noncontact orientation of objects in three-dimensional space using magnetic levitation. Proc. Natl. Acad. Sci. U. S. A. 2014, 111 (36), 12980-5.

(26) Mirica, K. A.; Phillips, S. T.; Shevkoplyas, S. S.; Whitesides, G. $\mathrm{M}$. Using magnetic levitation to distinguish atomic-level differences in 
chemical composition of polymers, and to monitor chemical reactions on solid supports. J. Am. Chem. Soc. 2008, 130 (52), 17678-80.

(27) Tasoglu, S.; Yu, C. H.; Liaudanskaya, V.; Guven, S.; Migliaresi, C.; Demirci, U. Magnetic Levitational Assembly for Living Material Fabrication. Adv. Healthcare Mater. 2015, 4 (10), 1469-76.

(28) Zhu, Y.; Kekalo, K.; Ndong, C.; Huang, Y.-Y.; Shubitidze, F.; Griswold, K. E.; Baker, I.; Zhang, J. X. J. Magnetic-Nanoparticle-Based Immunoassays-on-Chip: Materials Synthesis, Surface Functionalization, and Cancer Cell Screening. Adv. Funct. Mater. 2016, 26 (22), 3953-3972.

(29) Haisler, W. L.; Timm, D. M.; Gage, J. A.; Tseng, H.; Killian, T. C.; Souza, G. R. Three-dimensional cell culturing by magnetic levitation. Nat. Protoc. 2013, 8 (10), 1940-9.

(30) Jaganathan, H.; Gage, J.; Leonard, F.; Srinivasan, S.; Souza, G. R.; Dave, B.; Godin, B. Three-dimensional in vitro co-culture model of breast tumor using magnetic levitation. Sci. Rep. 2015, 4, 6468.

(31) Xu, F.; Wu, C. A.; Rengarajan, V.; Finley, T. D.; Keles, H. O.; Sung, Y.; Li, B.; Gurkan, U. A.; Demirci, U. Three-dimensional magnetic assembly of microscale hydrogels. Adv. Mater. 2011, 23 (37), 4254-60.

(32) Evrard, R.; Boutry, G. A. An Absolute Micromanometer Using Diamagnetic Levitation. J. Vac. Sci. Technol. 1969, 6 (2), 279-288.

(33) Andres, U. Magnetohydrodynamic \& magnetohydrostatic methods of mineral separation; Halsted Press: Sydney, Australia, 1976.

(34) Kelland, D.; Hiresaki, Y.; Friedlaender, F.; Takayasu, M. Diamagnetic particle capture and mineral separation. IEEE Trans. Magn. 1981, 17 (6), 2813-2815.

(35) Kendall, B. R. F.; Vollero, M. F.; Hinkle, L. D. Passive levitation of small particles in vacuum: Possible applications to vacuum gauging. J. Vac. Sci. Technol., A 1987, 5 (4), 2458-2462.

(36) Mirica, K. A.; Shevkoplyas, S. S.; Phillips, S. T.; Gupta, M.; Whitesides, G. M. Measuring densities of solids and liquids using magnetic levitation: fundamentals. J. Am. Chem. Soc. 2009, 131 (29), 10049-58.

(37) Berry, M. V.; Geim, A. K. Of flying frogs and levitrons. Eur. J. Phys. 1997, 18 (4), 307-313.

(38) Brandt, E. H. Theory catches up with flying frog. Phys. World 1997, 10 (9), 23-24.

(39) Geim, A. Everyone's Magnetism. Phys. Today 1998, 51 (9), 3639.

(40) Simon, M. D.; Geim, A. K. Diamagnetic levitation: Flying frogs and floating magnets (invited). J. Appl. Phys. 2000, 87 (9), 6200-6204.

(41) Nemiroski, A.; Kumar, A. A.; Soh, S.; Harburg, D. V.; Yu, H. D.; Whitesides, G. M. High-Sensitivity Measurement of Density by Magnetic Levitation. Anal. Chem. 2016, 88 (5), 2666-74.

(42) Zablotskii, V.; Lunov, O.; Kubinova, S.; Polyakova, T.; Sykova, E.; Dejneka, A. Effects of high-gradient magnetic fields on living cell machinery. J. Phys. D: Appl. Phys. 2016, 49 (49), 493003.

(43) Winkleman, A.; Perez-Castillejos, R.; Gudiksen, K. L.; Phillips, S. T.; Prentiss, M.; Whitesides, G. M. Density-based diamagnetic separation: devices for detecting binding events and for collecting unlabeled diamagnetic particles in paramagnetic solutions. Anal. Chem. 2007, 79 (17), 6542-50.

(44) Mirica, K. A.; Phillips, S. T.; Mace, C. R.; Whitesides, G. M. Magnetic levitation in the analysis of foods and water. J. Agric. Food Chem. 2010, 58 (11), 6565-9.

(45) Lyuksyutov, I. F.; Naugle, D. G.; Rathnayaka, K. D. D. On-chip manipulation of levitated femtodroplets. Appl. Phys. Lett. 2004, 85 (10), 1817.

(46) Lyuksyutov, I. F.; Lyuksyutova, A.; Naugle, D. G.; Rathnayaka, K. D. D. Trapping Microparticles with Strongly Inhomogeneous Magnetic Fields. Mod. Phys. Lett. B 2003, 17 (17), 935-940.

(47) Feinstein, E.; Prentiss, M. Three-dimensional self-assembly of structures using the pressure due to a ferrofluid in a magnetic field gradient. J. Appl. Phys. 2006, 99 (6), 064901.

(48) Chetouani, H.; Jeandey, C.; Haguet, V.; Rostaing, H.; Dieppedale, C.; Reyne, G. Diamagnetic Levitation With Permanent Magnets for Contactless Guiding and Trapping of Microdroplets and
Particles in Air and Liquids. IEEE Trans. Magn. 2006, 42 (10), 35573559.

(49) Winkleman, A.; Gudiksen, K. L.; Ryan, D.; Whitesides, G. M.; Greenfield, D.; Prentiss, M. A magnetic trap for living cells suspended in a paramagnetic buffer. Appl. Phys. Lett. 2004, 85 (12), 2411.

(50) Nemiroski, A.; Soh, S.; Kwok, S. W.; Yu, H. D.; Whitesides, G. M. Tilted Magnetic Levitation Enables Measurement of the Complete Range of Densities of Materials with Low Magnetic Permeability. J. Am. Chem. Soc. 2016, 138 (4), 1252-7.

(51) Zhao, W.; Zhu, T.; Cheng, R.; Liu, Y.; He, J.; Qiu, H.; Wang, L.; Nagy, T.; Querec, T. D.; Unger, E. R.; Mao, L. Label-Free and Continuous-Flow Ferrohydrodynamic Separation of HeLa Cells and Blood Cells in Biocompatible Ferrofluids. Adv. Funct. Mater. 2016, 26 (22), 3990-3998.

(52) Kose, A. R; Fischer, B.; Mao, L.; Koser, H. Label-free cellular manipulation and sorting via biocompatible ferrofluids. Proc. Natl. Acad. Sci. U. S. A. 2009, 106 (51), 21478-83.

(53) Wang, S.; Tasoglu, S.; Chen, P. Z.; Chen, M.; Akbas, R.; Wach, S.; Ozdemir, C. I.; Gurkan, U. A.; Giguel, F. F.; Kuritzkes, D. R.; Demirci, U. Micro-a-fluidics ELISA for rapid CD4 cell count at the point-of-care. Sci. Rep. 2015, 4, 3796.

(54) Yellen, B. B.; Hovorka, O.; Friedman, G. Arranging matter by magnetic nanoparticle assemblers. Proc. Natl. Acad. Sci. U. S. A. 2005, 102 (25), 8860-4.

(55) Alsberg, E.; Feinstein, E.; Joy, M. P.; Prentiss, M.; Ingber, D. E. Magnetically-guided self-assembly of fibrin matrices with ordered nano-scale structure for tissue engineering. Tissue Eng. 2006, 12 (11), 3247-56.

(56) Scott, K. L.; Hirano, T.; Yang, H.; Singh, H.; Howe, R. T.; Niknejad, A. M. High-Performance Inductors Using Capillary Based Fluidic Self-Assembly. J. Microelectromech. Syst. 2004, 13 (2), 300-309.

(57) Srinivasan, U.; Liepmann, D.; Howe, R. T. Microstructure to substrate self-assembly using capillary forces. J. Microelectromech. Syst. 2001, 10 (1), 17-24.

(58) Bowden, N. Self-Assembly of Mesoscale Objects into Ordered Two-Dimensional Arrays. Science 1997, 276 (5310), 233-235.

(59) Gracias, D. H.; Tien, J.; Breen, T. L.; Hsu, C.; Whitesides, G. M. Forming electrical networks in three dimensions by self-assembly. Science 2000, 289 (5482), 1170-1172.

(60) Tien, J.; Terfort, A.; Whitesides, G. M. Microfabrication through Electrostatic Self-Assembly. Langmuir 1997, 13 (20), 5349-5355.

(61) Dendukuri, D.; Hatton, T. A.; Doyle, P. S. Synthesis and selfassembly of amphiphilic polymeric microparticles. Langmuir 2007, 23 (8), 4669-74.

(62) Du, Y.; Lo, E.; Ali, S.; Khademhosseini, A. Directed assembly of cell-laden microgels for fabrication of 3D tissue constructs. Proc. Natl. Acad. Sci. U. S. A. 2008, 105 (28), 9522-7.

(63) Du, Y.; Ghodousi, M.; Lo, E.; Vidula, M. K.; Emiroglu, O.; Khademhosseini, A. Surface-directed assembly of cell-laden microgels. Biotechnol. Bioeng. 2010, 105 (3), 655-62.

(64) Hulteen, J. C. Nanosphere lithography: A materials general fabrication process for periodic particle array surfaces. J. Vac. Sci. Technol., A 1995, 13 (3), 1553.

(65) Ormonde, A. D.; Hicks, E. C.; Castillo, J.; Van Duyne, R. P. Nanosphere lithography: fabrication of large-area $\mathrm{Ag}$ nanoparticle arrays by convective self-assembly and their characterization by scanning UV-visible extinction spectroscopy. Langmuir 2004, 20 (16), 6927-31.

(66) Langer, R; Vacanti, J. P. Tissue engineering. Science 1993, 260 (5110), 920-6.

(67) Nam, K. H.; Smith, A. S.; Lone, S.; Kwon, S.; Kim, D. H. Biomimetic 3D Tissue Models for Advanced High-Throughput Drug Screening. J. Lab Autom 2015, 20 (3), 201-15.

(68) Gil, S.; Mano, J. F. Magnetic composite biomaterials for tissue engineering. Biomater. Sci. 2014, 2 (6), 812-818.

(69) Butler, D. L.; Hunter, S. A.; Chokalingam, K.; Cordray, M. J.; Shearn, J.; Juncosa-Melvin, N.; Nirmalanandhan, S.; Jain, A. Using functional tissue engineering and bioreactors to mechanically stimulate tissue-engineered constructs. Tissue Eng., Part A 2009, 15 (4), 741-9. 
(70) Martin, Y.; Vermette, P. Bioreactors for tissue mass culture: design, characterization, and recent advances. Biomaterials 2005, 26 (35), 7481-503.

(71) Martin, I.; Wendt, D.; Heberer, M. The role of bioreactors in tissue engineering. Trends Biotechnol. 2004, 22 (2), 80-6.

(72) Pei, M.; Solchaga, L. A.; Seidel, J.; Zeng, L.; Vunjak-Novakovic, G.; Caplan, A. I.; Freed, L. E. Bioreactors mediate the effectiveness of tissue engineering scaffolds. FASEB J. 2002, 16 (12), 1691-4.

(73) Pregibon, D. C.; Toner, M.; Doyle, P. S. Magnetically and biologically active bead-patterned hydrogels. Langmuir 2006, 22 (11), 5122-8.

(74) Yi, C.; Li, C.-W.; Ji, S.; Yang, M. Microfluidics technology for manipulation and analysis of biological cells. Anal. Chim. Acta 2006, 560 (1-2), 1-23.

(75) Andersson, H.; van den Berg, A. Microfabrication and microfluidics for tissue engineering: state of the art and future opportunities. Lab Chip 2004, 4 (2), 98-103.

(76) Okuyama, T.; Yamazoe, H.; Mochizuki, N.; Khademhosseini, A.; Suzuki, H.; Fukuda, J. Preparation of arrays of cell spheroids and spheroid-monolayer cocultures within a microfluidic device. J. Biosci Bioeng 2010, 110 (5), 572-6.

(77) Furdui, V. I.; Harrison, D. J. Immunomagnetic T cell capture from blood for PCR analysis using microfluidic systems. Lab Chip 2004, 4 (6), 614-8.

(78) Kaji, H.; Camci-Unal, G.; Langer, R.; Khademhosseini, A. Engineering systems for the generation of patterned co-cultures for controlling cell-cell interactions. Biochim. Biophys. Acta, Gen. Subj. 2011, 1810 (3), 239-50.

(79) Khademhosseini, A.; Langer, R.; Borenstein, J.; Vacanti, J. P. Microscale technologies for tissue engineering and biology. Proc. Natl. Acad. Sci. U. S. A. 2006, 103 (8), 2480-7.

(80) Gauvin, R.; Chen, Y. C.; Lee, J. W.; Soman, P.; Zorlutuna, P.; Nichol, J. W.; Bae, H.; Chen, S.; Khademhosseini, A. Microfabrication of complex porous tissue engineering scaffolds using 3D projection stereolithography. Biomaterials 2012, 33 (15), 3824-34.

(81) Truskett, V. N.; Watts, M. P. Trends in imprint lithography for biological applications. Trends Biotechnol. 2006, 24 (7), 312-7.

(82) Arslan-Yildiz, A. Unpublished Results, 2017.

(83) Song, S.; Xu, H.; Fan, C. Potential diagnostic applications of biosensors: current and future directions. International journal of nanomedicine 2006, 1 (4), 433.

(84) McGlennen, R. C. Miniaturization technologies for molecular diagnostics. Clinical Chemistry 2001, 47 (3), 393-402.

(85) Baday, M.; Calamak, S.; Durmus, N. G.; Davis, R. W.; Steinmetz, L. M.; Demirci, U. Integrating Cell Phone Imaging with Magnetic Levitation (i-LEV) for Label-Free Blood Analysis at the Point-of-Living. Small 2016, 12 (9), 1222-9.

(86) Yager, P.; Edwards, T.; Fu, E.; Helton, K.; Nelson, K.; Tam, M. R.; Weigl, B. H. Microfluidic diagnostic technologies for global public health. Nature 2006, 442 (7101), 412-8.

(87) Subramaniam, A. B.; Gonidec, M.; Shapiro, N. D.; Kresse, K. M.; Whitesides, G. M. Metal-amplified Density Assays, (MADAs), including a Density-Linked Immunosorbent Assay (DeLISA). Lab Chip 2015, 15 (4), 1009-22.

(88) Knowlton, S.; Yu, C. H.; Jain, N.; Ghiran, I. C.; Tasoglu, S. Smart-Phone Based Magnetic Levitation for Measuring Densities. PLoS One 2015, 10 (8), e0134400.

(89) Timm, D. M.; Chen, J.; Sing, D.; Gage, J. A.; Haisler, W. L.; Neeley, S. K.; Raphael, R. M.; Dehghani, M.; Rosenblatt, K. P.; Killian, T. C.; Tseng, H.; Souza, G. R. A high-throughput three-dimensional cell migration assay for toxicity screening with mobile device-based macroscopic image analysis. Sci. Rep. 2013, 3, 3000.

(90) Tseng, H.; Gage, J. A.; Shen, T.; Haisler, W. L.; Neeley, S. K.; Shiao, S.; Chen, J.; Desai, P. K.; Liao, A.; Hebel, C.; Raphael, R. M.; Becker, J. L.; Souza, G. R. A spheroid toxicity assay using magnetic 3D bioprinting and real-time mobile device-based imaging. Sci. Rep. 2015, 5, 13987.

(91) Tseng, H.; Gage, J. A.; Haisler, W. L.; Neeley, S. K.; Shen, T.; Hebel, C.; Barthlow, H. G.; Wagoner, M.; Souza, G. R. A high- throughput in vitro ring assay for vasoactivity using magnetic 3D bioprinting. Sci. Rep. 2016, 6, 30640.

(92) Souza, G. R.; Tseng, H.; Gage, J. A.; Mani, A.; Desai, P.; Leonard, F.; Liao, A.; Longo, M.; Refuerzo, J. S.; Godin, B. Magnetically Bioprinted Human Myometrial 3D Cell Rings as A Model for Uterine Contractility. Int. J. Mol. Sci. 2017, 18 (4), 683.

(93) Tasoglu, S.; Khoory, J. A.; Tekin, H. C.; Thomas, C.; Karnoub, A. E.; Ghiran, I. C.; Demirci, U. Levitational Image Cytometry with Temporal Resolution. Adv. Mater. 2015, 27 (26), 3901-8. 